\title{
Effect of golden needle mushroom (Flammulina velutipes) stem waste on laying performance, calcium utilization, immune response and serum immunity at early phase of production
}

\author{
Shad Mahfuz ${ }^{1,2}$, Hui Song ${ }^{1,3, *}$, Zhongjun Liu ${ }^{4}$, Xinyu Liu', Zipeng Diao', \\ Guihong Ren ${ }^{1,5}$, Zhixin Guo ${ }^{1,6}$, and Yan Cui ${ }^{1,7}$
}

\footnotetext{
* Corresponding Author: Hui Song Tel: +86-13604449943, Fax: +86-43184532885, E-mail: songhuinongda@163.com

'School of Life Science, Jilin Agricultural University, Changchun 130118, China

2 Department of Animal Nutrition, Sylhet Agricultural University, Sylhet 3100, Bangladesh

${ }^{3}$ Engineering Research Center of Chinese Ministry

of Education for Edible and Medicinal Fungi,

Changchun 130118, China

${ }^{4}$ College of Chinese Medicine Materials, Jilin

Agricultural University, Changchun 130118, China

${ }^{5}$ School of Chemistry and Biology, Beihua University, Jilin 132013, China

${ }^{6}$ College of Live Science, Tonghua Normal University, Tonghua, Jilin 134001, China

${ }^{7}$ College of Animal Science and Veterinary Medicine,

Jinzhou Medical University, Jinzhou 121001, China

ORCID

Shad Mahfuz

https://orcid.org/0000-0001-8191-3028

Hui Song

https://orcid.org/0000-0002-4505-9204
}

Submitted Oct 29, 2017; Revised Dec 29, 2017; Accepted Feb 8, 2018
Objective: This experiment was conducted to evaluate the effects of golden needle mushroom (Flammulina velutipes) stem waste (FVW), on organic eggs production, calcium utilization, antibody response, serum immunoglobulin, and serum cytokine concentration at early phase of production in laying hens.

Methods: A total 210, 19 weeks old aged ISA Brown layers were randomly assigned into 5 equal treatment groups, with 7 replications of 6 hens each. Dietary treatment included a standard basal diet as control; antibiotic (0.05\% flavomycin); $2 \%$ FVW; $4 \%$ FVW; and $6 \%$ FVW. The experimental duration was 10 weeks.

Results: There was no significant differences ( $p>0.05$ ) on hen day egg production, egg weight, egg mass, feed intake, and feed conversion ratio (FCR) among experimental groups. Unmarketable eggs were significantly lower $(\mathrm{p}<0.05)$ both in $4 \%$ FVW and $6 \%$ FVW fed groups than control group. The calcium retention and calcium in egg shell deposition were significantly higher $(\mathrm{p}<0.05)$ in FVW inclusion groups than control and antibiotic groups. Antibody titers against Newcastle diseases were significantly higher $(\mathrm{p}<0.05)$ in 6\% FVW fed group (except combined with $4 \% \mathrm{FVW}$ at day 147 ) and infectious bronchitis were significantly higher ( $<<$ 0.05 ) in FVW fed groups (except 2\% FVW and 4\% FVW at day 161) than control and antibiotic groups. Serum immunoglobulin sIgA was significantly higher $(\mathrm{p}<0.05)$ in all levels of FVW and IgG was significantly higher $(\mathrm{p}<0.05)$ in $4 \%$ FVW than control and antibiotic groups. Serum cytokine concentration interleukin-2 (IL-2) was significantly higher $(\mathrm{p}<0.05)$ in $6 \%$ FVW; IL-6 and tumor necrotic factor- $a$ were significantly higher $(\mathrm{p}<0.05)$ both in $4 \%$ FVW and 6\% FVW than control and antibiotic groups; IL-4 was significantly higher $(\mathrm{p}<0.05)$ in antibiotic, 2\% FVW and 4\% FVW fed groups than control.

Conclusion: F. velutipes mushroom waste can be used as a novel substitute for antibiotic for organic egg production and sound health status in laying hens.

Keywords: Laying Hens; Mushroom Waste; Laying Performance; Calcium Utilization; Antibody Response; Serum Immunity

\section{INTRODUCTION}

Golden needle mushroom (Flammulina velutipes [F. velutipes]) is one of the main edible mushrooms long recognized for its nutritional value and delicious taste in Asian countries especially China, Japan, Vietnam and Korea. F. velutipes fungus belonging to the family Physalacriaceae is also known as winter mushroom or lily mushroom or velvet stem or enoki mushroom among different countries [1]. Having nutritional values, folk medicine has long recognized this mushroom for wide spectrum of therapeutic and prophylactic uses [2]. Many bioactive constituents from a range of families have been isolated from different parts of 
the mushroom, including carbohydrates, protein, lipids, glycoproteins, phenols, and sesquiterpenes [3]. In addition, bioactive substances like sterol, sesquiteropenoids and its compound sterpurol, flammulinol-A, enokipodin isolated from $F$. velutipes mushroom have strong antioxidant, cholesterol lowering effects, anti-inflammatory, immune modulatory, antibacterial, antifungal, and cytotoxic effects [4,5]. Low calories, good fiber food, protein with all the essential amino acids, adequate minerals and vitamins in F. velutipes were reported by Wu et al [6]. During the last several decades, antibiotic has been widely used in the poultry industry to promote growth. Moreover, the extensive use of antibiotic has the possibility to generate antibiotic resistant bacteria in animal products [7]. Usage of antibiotic as an animal growth promoter in animal diets has been banned or limited in many countries [8]. Due to recent ban of using antibiotic as growth promoters in poultry diet, fungi or herbs that have been used as feed supplements for centuries in veterinary medicine [9] and mushroom waste could be a proper substitute for antibiotics [10]. Cultivation of mushroom has become popular which leads stem waste material available but its utilization is still limited.

However, there is little information available till date about the effects of mushroom waste on layer production and health parameters. Based on the previously reported favorable effects of mushroom in an in vitro study, the current study was designed to evaluate the effects of $F$. velutipes stem waste (FVW) on egg production, calcium utilization, immune response, serum immunity, and serum cytokine concentration in layers at the early phase of production.

\section{MATERIALS AND METHODS}

\section{Experimental hens and diets}

A total 210 ISA Brown laying hens of 19 weeks old were randomly assigned into 5 equal treatment groups, with 7 replications of 6 hens for each treatment. The experiment was carried out at the animal shed building and handling with experimental hens was approved by the animal care and use committee of Jilin Agricultural University. Three hens were kept together in one cage and house temperature was maintained at approximately $24^{\circ} \mathrm{C}$. The hens were exposed to a 16 hour light and 8 hour dark period throughout the experiment period of 10 weeks, from 19 weeks to 29 weeks.

Hens were given a standard basal diet considered as control group; antibiotic ( $0.05 \%$ flavomycin) group; $2 \% \mathrm{FVW}$ fed group; $4 \%$ FVW fed group; and 6\% FVW fed group respectively. Feed and water were offered ad libitum during the whole experimental period of 70 days. The $F$. velutipes stem was collected from a domestic mushroom farm in Changchun, China. The collected mushroom stem was properly dried under sun and transferred to feed mill for further uses. Mushroom and antibiotic were mixed with layer diet by a feed mixer in Feed
Mill (Jilin Hanghong Animal Husbandry Co. Ltd, Changchun, China). The nutritional requirement was followed according to the recommendations of the genetic line manual [11].

\section{Laying performance}

Eggs from all replicated cages were collected and recorded daily. Egg production percentage was calculated by dividing the total number of eggs by hen-day and was expressed in percent. Egg weight was presented as the average egg weight per hen divided by the number of days during the experimental period. Egg mass was calculated as laying percentage multiplied by egg weight. Total feed intake was determined as the differences between feed offered and residual feed in trough feeders on weekly basis. Feed conversion ratio (FCR) was then calculated as feed intake divided by egg mass respectively. Unmarketable eggs were calculated on number of curled eggs (abnormal size, shape, color, deformities, broken eggs, etc) divided by the total number of eggs laid per pen and expressed in percent during the total experimental period.

\section{Chemical analysis of feed sample}

Mushroom stem waste (FVW) sample and diet sample were prepared $(0.01 \mathrm{~mm})$ for proximate component analysis. The analyzed nutritional composition of the experimental diet and FVW are presented in Table 1. The dry matter (DM) (method number 934.01), ether extract (EE) (method number 920.39), crude fiber (Method number 962.09), and total ash (method number 942.05) were analyzed according to the procedures of AOAC [12]. Nitrogen was determined using an FP-528 nitrogen determinator (LECO Corporation, Joseph, MI, USA). The calcium and phosphorus content were determined following the method of Talapatra et al [13].

\section{Calcium utilization}

Samples of feed, excreta, and egg shell (3 eggs from each replicate, $\mathrm{n}=105$ ) from each replicated treatment groups were collected every 24 hour during the last three consecutive days of the experiment. Samples were dried in oven at $105^{\circ} \mathrm{C}$ for 24 hour, ground by laboratory high speed universal sample grinder (Huanghua xinxing electric Appliance Co, Hebei, China) and then ashed in a muffle furnace at $650^{\circ} \mathrm{C}$ for 6 hour. The calcium retention was calculated by deduction of calcium found in excreta from calcium intake in feed. The calcium balance was estimated by deduction of calcium in egg shell from calcium retention. Apparent calcium retention and mass calcium balance were determined according to the procedure described by Abdelqader et al [14].

\section{Vaccination and immunological analyses}

All birds were immunized, with combined vaccine of Newcastle diseases (ND); infectious bronchitis (IB) and egg drop syndrome vaccine, inactivated (strain La Sota+Strain M41+ 
Table 1. Ingredients and nutrient composition of the diets for layers $(\mathrm{g} / \mathrm{kg})$

\begin{tabular}{|c|c|c|c|c|c|}
\hline Items & Control & Antibiotic & $2 \% \mathrm{FVW}^{1)}$ & $4 \% \mathrm{FVW}^{1)}$ & $6 \% \mathrm{FVW}^{11}$ \\
\hline \multicolumn{6}{|l|}{ Ingredients } \\
\hline Maize corn & 557.0 & 556.5 & 544.0 & 525.0 & 510.0 \\
\hline Soyabean oil & 28.0 & 28.0 & 26.0 & 28.0 & 25.0 \\
\hline $\mathrm{FVW}^{2)}$ & - & - & 20.0 & 40.0 & 60.0 \\
\hline Lysine & 2.0 & 2.0 & 2.0 & 2.0 & 2.0 \\
\hline Dicalcium & 36.0 & 36.0 & 36.0 & 36.0 & 36.0 \\
\hline Limestone & 88.0 & 88.0 & 88.0 & 88.0 & 88.0 \\
\hline Common salt & 2.5 & 2.5 & 2.5 & 2.5 & 2.5 \\
\hline Vit-mineral premix ${ }^{3)}$ & 2.0 & 2.0 & 2.0 & 2.0 & 2.0 \\
\hline Antibiotics & - & 0.5 & - & - & - \\
\hline Total & 1,000 & 1,000 & 1,000 & 1,000 & 1,000 \\
\hline Calcium & 41.10 & 41.09 & 41.11 & 41.10 & 41.2 \\
\hline Phosphorus & 7.20 & 7.18 & 7.22 & 7.21 & 7.20 \\
\hline $\mathrm{EE}$ & 52.3 & 52.3 & 50.40 & 52.20 & 49.30 \\
\hline $\mathrm{CF}$ & 25.6 & 25.5 & 29.60 & 33.7 & 37.90 \\
\hline \multicolumn{6}{|l|}{ Calculated analysis ( $\mathrm{g} / \mathrm{kg})$} \\
\hline ME (MJ/kg) & 11.70 & 11.69 & 11.70 & 11.71 & 11.71 \\
\hline Lysine & 10.51 & 10.51 & 10.40 & 10.45 & 10.43 \\
\hline Methionine & 5.0 & 5.0 & 5.0 & 4.9 & 4.9 \\
\hline Linoleic acid & 11.1 & 11.1 & 11.2 & 11.15 & 11.21 \\
\hline Arginine & 10.5 & 10.5 & 10.7 & 10.6 & 10.6 \\
\hline Threonine & 5.52 & 5.5 & 5.6 & 5.7 & 5.65 \\
\hline
\end{tabular}

FVW, Flammulina velutipes mushroom stem waste; DM, dry matter; $C P$, crude protein; $E E$, ether extract; $C F$, crude fiber; ME, metabolizable energy.

1) FVW, Flammulina velutipes stem waste at $2 \%, 4 \%$, and $6 \%$.

2) FVW, analyzed composition of $F$. velutipes mushroom stem waste $(\mathrm{g} / \mathrm{kg}$ ) DM 889.0 \pm 0.85 ; CP 12.75 \pm 0.49 ; CF 21.05 \pm 0.106 ; EE 2.7 \pm 0.014 ; total minerals (ash) $11.5 \pm 0.085$; calcium $4.0 \pm 0.1$; phosphorus $6.2 \pm 0.28$; value are expressed as mean \pm standard deviation $(n=6)$.

3) Provided per kg of the complete diet: retinyl acetate, 4,500 IU; cholecalciferol, 1,200 IU; DL- $\alpha$-tocopheryl acetate, 25,000 IU; thiamin, 5,000 mg; riboflavin, $20,000 \mathrm{mg}$; phylloquinone, 10,000 mg; niacin, 45,000 mg; pantothenic acid, 35,000 mg; biotin, 1,500 mg; folic acid, 3,000 mg; cyanocobalamin, 40 mg; zinc, 45 mg; manganese 50 mg; iron, $30 \mathrm{mg}$; copper, $4 \mathrm{mg}$; cobalt, $120 \mu \mathrm{g}$; iodine, $1 \mathrm{mg}$; selenium, $120 \mu \mathrm{g}$.

Strain HSH23, Beijing Ceva Huadu Biological Co, Ltd, Beijing, China) at day 140 via wing web $(0.5 \mathrm{~mL} / \mathrm{bird})$. A blood sample was obtained from one bird of each replicated pen ( 7 birds per experimental group) via wing vein on day 147 , day 154 , day 161 , and day 203. On the respective day of blood sample collection, serum was obtained by centrifuged at $3,000 \times \mathrm{g}$ for $20 \mathrm{~min}$ at $4^{\circ} \mathrm{C}$ (Legend Micro 17R centrifuge, Thermo Fisher, Am Kalkberg, Germany) and was stored at $-80^{\circ} \mathrm{C}$ until measuring antibody titers, serum immunoglobulin and serum cytokine concentration. Commercial enzyme-linked immunesorbent assay kits (Shanghai Jianglai industrial Ltd, Shanghai, China) were used to analyze ND and IB antibody titers. The serum immunoglobulin A (sIgA), immunoglobulin G (IgG), interleukin-2 (IL-2), IL-4, IL-6, and tumor necrotic factor- $\alpha$ (TNF- $\alpha$ ) were measured using chicken specific sIgA, IgG, IL-2, IL-4, IL-6, TNF- $\alpha$ ELISA Quantitation Kits (Shang Hai Leng- ton Biosicences Co. Ltd, Shang Hai, China) according to the instructions of the manufacturer and absorbance were measured at $450 \mathrm{~nm}$.

\section{Statistical analysis}

Data were subjected to one-way analysis of variance using SPSS (2006) software [15]. Significant effects of dietary treatments on experimental groups were evaluated with Duncan's test [16]. Statements of statistical significance are based on a probability of $\mathrm{p}<0.05$.

\section{RESULTS}

\section{Laying hen performance}

There were no significant $(\mathrm{p}>0.05)$ differences on hen day egg production, egg weight, egg mass, feed intake, feed conversion 
efficiency (FCR) and live weight among experimental groups during the entire 70 days study period (Table 2). Unmarketable eggs were lower $(\mathrm{p}<0.05)$ in $4 \% \mathrm{FVW}$ and $6 \% \mathrm{FVW}$ fed groups than control. However, egg weight, egg mass were found higher with improved FCR in FVW fed groups compared with control and antibiotic fed groups although the results were not significant (Table 2).

\section{Calcium utilization in layer}

The calcium retention was improved $(\mathrm{p}<0.05)$ in FVW fed groups compared with control and antibiotic group although there were no differences on total calcium intake among the treatment groups. The calcium excretion in excreta was lower $(\mathrm{p}<0.05)$ in FVW fed group than control and antibiotic groups. The calcium in egg shell deposition was found higher $(\mathrm{p}<0.05)$ in FVW inclusion groups than control and antibiotic groups. There was no significant ( $\mathrm{p}>0.05)$ differences in calcium balance among experimental groups (Table 3 ).

\section{Immune response on vaccines}

Feeding layers on diets with FVW resulted in a significant higher $(\mathrm{p}<0.05)$ in the antibody titers against ND in 6\% FVW fed group (except combine with $4 \%$ FVW at day 147) than control and antibiotic fed groups. On the other hand, antibody titers against IB virus vaccines were significantly higher $(\mathrm{p}<0.05)$ in FVW fed groups (except 2\% FVW and 4\% FVW at day 161) in comparison to those fed on the control diets and antibiotic diets. The best responses for antibody titers were found in layer fed on diets containing 6\% FVW. Interestingly negative antibody titers were observed for IB with antibiotic fed group at day 161 whereas mushroom fed groups showed highly positive in the defined period (Table 4 ).

\section{Serum immunoglobulin and serum cytokines concentration}

The sIgA and IgG were increased significantly $(\mathrm{p}<0.05)$ in FVW fed groups compared with control and antibiotic groups in this study (Table 5). The highest concentration for sIgA and IgG was observed in $4 \%$ FVW fed group among the treatments. Serum cytokine concentration (IL-2) was significantly higher $(\mathrm{p}<0.05)$ in $6 \%$ FVW; IL-6 and TNF- $\alpha$ were significantly higher $(\mathrm{p}<0.05)$ both in $4 \%$ FVW and $6 \%$ FVW than control and antibiotic fed groups. Moreover, IL-4 was found significantly higher $(\mathrm{p}<0.05)$ in antibiotic, $2 \% \mathrm{FVW}$ and $4 \%$ FVW fed groups when compared with control (Table 5).

\section{DISCUSSION}

Demand for applying medicinal and functional natural herbs in chicken rations is increasing to improve health status as well as production performance after the ban of antimicrobial growth promoters (antibiotics) in different countries [17]. The estimated value of DM, crude protein (CP), crude fiber (CF) in FVW were mostly close to previously reported values $[18,19]$

Table 2. Effect of Flammulina velutipes mushroom stem waste (FVW) on performance in laying hens ${ }^{1)}$

\begin{tabular}{|c|c|c|c|c|c|c|c|}
\hline Parameters & Control & Antibiotic & $2 \% \mathrm{FVW}$ & $4 \% \mathrm{FVW}$ & $6 \% \mathrm{FVW}$ & SEM & $p$-value \\
\hline Hen day egg production (\%) & 84.74 & 84.45 & 83.95 & 89.92 & 85.89 & 1.345 & 0.654 \\
\hline Egg weight (g/egg) & 57.41 & 57.50 & 58.22 & 58.14 & 58.79 & 0.433 & 0.865 \\
\hline Egg mass (g/d/hen) & 48.81 & 48.57 & 48.95 & 52.36 & 50.53 & 0.988 & 0.740 \\
\hline Feed intake (g/d/hen) & 111.25 & 111.06 & 110.20 & 111.17 & 111.13 & 0.490 & 0.966 \\
\hline FCR $(g / g)$ & 2.39 & 2.32 & 2.31 & 2.15 & 2.23 & 0.048 & 0.619 \\
\hline Unmarketable eggs (\%) & $1.21^{\mathrm{a}}$ & $0.89^{\mathrm{ab}}$ & $0.89^{\mathrm{ab}}$ & $0.41^{b}$ & $0.39^{b}$ & 0.098 & 0.025 \\
\hline Initial live weight (gm) & $1,709.86$ & $1,715.58$ & $1,707.14$ & $1,713.57$ & $1,712.43$ & 2.987 & 0.918 \\
\hline Final live weight (gm) & $1,843.29$ & $1,849.71$ & $1,839.29$ & $1,845.57$ & $1,844.14$ & 5.917 & 0.981 \\
\hline
\end{tabular}

SEM, pooled standard error of the means; $F C R$, feed conversion ratio.

1) Data represent the mean value of 7 replicates with 6 hens each treatment.

$a, b$ Means in the same row with different letters are significantly different $(p<0.05)$.

Table 3. Effect of Flammulina velutipes mushroom stem waste (FVW) on calcium utilization in layer ${ }^{1)}$

\begin{tabular}{|c|c|c|c|c|c|c|c|}
\hline Parameters & Control & Antibiotic & $2 \% \mathrm{FVW}$ & $4 \% \mathrm{FVW}$ & $6 \% \mathrm{FVW}$ & SEM & $p$-value \\
\hline Ca intake in feed ( $\mathrm{g} / \mathrm{d})$ & 4.59 & 4.57 & 4.53 & 4.57 & 4.57 & 0.015 & 0.718 \\
\hline Ca in excreta $(\mathrm{g} / \mathrm{d})$ & $2.72^{\mathrm{a}}$ & $2.69^{\mathrm{a}}$ & $2.32^{b}$ & $2.16^{c}$ & $2.20^{b c}$ & 0.045 & 0.001 \\
\hline Ca retention (g/d) & $1.88^{c}$ & $1.88^{c}$ & $2.20^{\mathrm{b}}$ & $2.41^{\mathrm{a}}$ & $2.37^{\mathrm{ab}}$ & 0.048 & 0.001 \\
\hline Ca in egg shell (g) & $1.79^{b}$ & $1.80^{\mathrm{b}}$ & $2.12^{\mathrm{a}}$ & $2.24^{\mathrm{a}}$ & $2.19^{a}$ & 0.040 & 0.001 \\
\hline Ca balance (g/d) & 0.08 & 0.08 & 0.08 & 0.17 & 0.18 & 0.016 & 0.061 \\
\hline
\end{tabular}

SEM, pooled standard error of the means.

1) Data represent the mean value of 7 replicates each treatment.

$a, b, c$ Means in the same row with different letters are significantly different $(p<0.05)$. 
Table 4. Effect of Flammulina velutipes mushroom stem waste (FVW) on antibody titers in layers ${ }^{1)}$

\begin{tabular}{|c|c|c|c|c|c|c|c|}
\hline Parameters & Control & Antibiotic & $2 \% \mathrm{FVW}$ & $4 \% \mathrm{FVW}$ & $6 \% \mathrm{FVW}$ & SEM & $p$-value \\
\hline \multicolumn{8}{|c|}{ Newcastle disease (ND) (ng/L) } \\
\hline Day 147 & $497.67^{\mathrm{ab}}$ & $328.50^{c}$ & $396.00^{b c}$ & $574.33^{\mathrm{a}}$ & $620.17^{\mathrm{a}}$ & 33.341 & 0.004 \\
\hline Day 161 & $271.00^{b}$ & $207.17^{b}$ & $251.17^{b}$ & $372.67^{\mathrm{ab}}$ & $458.50^{\mathrm{a}}$ & 31.218 & 0.037 \\
\hline \multicolumn{8}{|c|}{ Infectious bronchitis $(\mathrm{IB})^{2)}$} \\
\hline Day 147 & $0.63^{\mathrm{bc}}$ & $0.52^{c}$ & $0.87^{\mathrm{ab}}$ & $1.00^{\mathrm{a}}$ & $1.12^{\mathrm{a}}$ & 0.070 & 0.006 \\
\hline
\end{tabular}

SEM, pooled standard error of the means.

1) Data represented the mean value of 7 hens per treatment.

${ }^{2)}$ Data represented more than cut off value $(>0.228)$ indicates positive $(+)$ for IB antibody as per kits instruction manual.

$a, b, c$ Means in the same row with different letters are significantly different $(p<0.05)$.

Table 5. Effect of Flammulina velutipes mushroom stem waste (FVW) on serum immunoglobulin and serum cytokine concentration in layers ${ }^{1)}$

\begin{tabular}{|c|c|c|c|c|c|c|c|}
\hline Parameters & Control & Antibiotic & $2 \% \mathrm{FVW}$ & $4 \%$ FVW & $6 \% \mathrm{FVW}$ & SEM & $p$-value \\
\hline $\operatorname{slgA}(\mu \mathrm{g} / \mathrm{mL})$ & $16.51^{b}$ & $18.35^{b}$ & $23.13^{\mathrm{a}}$ & $24.79^{a}$ & $22.43^{a}$ & 0.790 & 0.001 \\
\hline $\lg G(\mathrm{mg} / \mathrm{mL})$ & $6.96^{b}$ & $7.82^{b}$ & $7.85^{b}$ & $10.82^{\mathrm{a}}$ & $8.44^{b}$ & 0.307 & 0.000 \\
\hline IL-2 (ng/L) & $12.68^{d}$ & $23.92^{b}$ & $16.67^{c}$ & $21.79^{b}$ & $28.16^{\mathrm{a}}$ & 1.057 & 0.000 \\
\hline IL-4 (ng/L) & $205.83^{b}$ & $257.64^{\mathrm{a}}$ & $249.34^{\mathrm{a}}$ & $258.21^{a}$ & $233.55^{\mathrm{ab}}$ & 5.952 & 0.017 \\
\hline IL-6 (ng/L) & $105.71^{b}$ & $124.80^{b}$ & $102.64^{b}$ & $223.30^{a}$ & $184.55^{\mathrm{a}}$ & 11.820 & 0.001 \\
\hline TNF- $\alpha$ (ng/L) & $607.79^{b}$ & $693.43^{b}$ & $581.14^{b}$ & $831.14^{a}$ & $748.86^{a}$ & 36.067 & 0.001 \\
\hline
\end{tabular}

SEM, pooled standard error of the means; slgA, serum immunoglobulin A; IgG, immunoglobulin G; IL, interleukin; TNF- $\alpha$, tumor necrotic factor- $\alpha$.

1) Data represented the mean value of 7 hens per treatment.

$a, b, c, d$ Means in the same row with different letters are significantly different $(p<0.05)$.

but EE, calcium and phosphorus were lower than the published values (EE, 18.4 to $73.3 \mathrm{~g} / \mathrm{kg}$; calcium 4.6 to $11.8 \mathrm{~g} / \mathrm{kg}$; and phosphorus 8.8 to $9.4 \mathrm{~g} / \mathrm{kg}$ ) [19,20]. These differences were associated with effects of soil, cultivation methods and environmental factors.

During the entire study period, this study did not find any significant differences in the measured laying parameters; hen day egg production, average egg weight, egg mass, FCR, among experimental groups. However, better laying performance was observed in layer fed on diets with 4\% FVW and 6\% FVW respectively. The present study was similar with the past study by Hong-Gu et al [21] who reported that fermented F. velutipes mycelium had no significant effects on egg production, egg mass, feed intake and FCR in laying hens. In addition $\mathrm{Na}$ et al [22] reported that inclusion of $F$. velutipes media at $5 \%$ to $10 \%$ in layer diets had no significant effects on egg production, egg weight, egg mass, and FCR. Lee et al [18] reported that higher levels up to 5\% F. velutipes mycelium did not improve feed intake in broiler which was similar with the current study for feed intake. Unmarketable eggs were significantly lower in 4\% FVW and 6\% FVW fed groups, which was associated with higher calcium deposition in egg shell with dietary inclusion of FVW in the experimental groups. Enhancing calcium availability and absorption in gut of hens could be potential strategy for improving egg shell quality as well as reducing unmarketable eggs from aged hens [14]. This study confirmed the beneficial effects of dietary inclusion with FVW on calcium utilization. This study speculated that dietary calcium source from FVW fed groups may improve calcium absorption, resulted higher calcium retention and calcium deposition in egg shell. F. velutipes is excellent source of vitamin and minerals especially calcium and phosphorus [23]. Lower calcium retention in control and antibiotic groups were found in the present study, which was because of higher fecal calcium excretion in experimental hens.

Antibody titers against ND and IB were found higher in $6 \%$ FVW fed group in this study. The combination of garlic, oyster mushroom and propolis extract to the diets improved antibody response to ND when compared to control and antibiotic diets in broilers [24]. In contrast, Fard et al [10] found no significant differences for ND antibody titers in broilers fed with $1 \%$ oyster mushroom waste and suggested a reinvestigation of the antibody titer with mushroom supplement. These differences might be correlated with mushroom type and inclusion levels with experimental birds.

This study also confirmed the significant positive effects of FVW on serum immunoglobulin and cytokine production in layer. The appropriate level of immune modulatory materials such as polysaccharides, protein, and some flavonoids are reported to maintain the immune response in host [25] and 
cytokines are known to be regulators of the immune status [26]. The activity of IL-2 is mainly manifested as activation of $B$ and T lymphocytes and NK cells [27]. Stimulation of the Th1 response is characterized by secretion of IL-2, TNF- $\alpha$ along with other cytokines which leads to the promotion of cellular immune mechanisms. Further stimulation of the Th2 response is characterized by secretion of IL-4, with other cytokines which promotes the humoral mechanisms of the immune response [28]. The polysaccharides in $F$. velutipes mushroom have strong immune modulatory activity and possess antioxidant activity that could enhance non-specific and specific immune responses in vitro [5]. Supplementation of $\beta$-glucan from edible mushroom had significant immune stimulatory effects in broiler birds that were reflected in the in vitro immune effector activities of the mucosal cells [29]. In addition, Badalyan and Hambardzumyan [30] stated that F. velutipes has immune modulatory effects via induction of cytokines. However, published data on the response of serum immunity and cytokine production with dietary FVW in layer are very limited to compare the current study.

\section{CONCLUSION}

In conclusion, present study highlighted the beneficial effects of FVW on immune response, serum immunity, calcium utilization, marketable eggs in laying hens without hampering egg production percent, egg weight and FCR. With a focus on organic egg production and sound health; golden needle mushroom (F. velutipes) stem waste can be used as a natural potential substitute for antibiotic in layer production.

\section{CONFLICT OF INTEREST}

We certify that there is no conflict of interest with any financial organization regarding the material discussed in the manuscript.

\section{ACKNOWLEDGMENTS}

This work was supported by "Innovation Platform for Economic Fungi in Jilin Province (Grant No. 2014-2016)" Changchun, P.R. China.

\section{REFERENCES}

1. Jing P, Zhao SJ, Lu MM, et al. Multiple-fingerprint analysis for investigating quality control of Flammulina velutipes fruiting body polysaccharides. J Agri Food Chem 2014;62:12128-33.

2. Tang C, Hoo PCX, Tan LTH, et al. Golden needle mushroom: a culinary medicine with evidenced-based biological activities and health promoting properties. Front Pharmacol 2016;7:474.

3. Yang W, Fang Y, Liang J, Hu Q. Optimization of ultrasonic extraction of Flammulina velutipes polysaccharides and evaluation of its acetylcholinesterase inhibitory activity. Food Res Int 2011;44:1269-75.

4. Wang Y, Bao L, Yang X, et al. Bioactive sesquiterpenoids from the solid culture of the edible mushroom Flammulina velutipes growing on cooked rice. Food Chem 2012;132:1346-53.

5. Wu M, Luo X, Xu X, et al. Antioxidant and immunomodulatory activities of a polysaccharide from Flammulina velutipes. J Tradit Chin Med 2014;34:733-40.

6. Wu D-m, Duan WQ, Liu Y, Cen Y. Anti-inflammatory effect of the polysaccharides of golden needle mushroom in burned rats. Int J Bio Macromol 2010;46:100-3.

7. Zhang D, Hu H, Rao Q, Zhao Z. Synergistic effects and physiological responses of selected bacterial isolates from animal feed to four natural antimicrobials and two antibiotics. Foodborne Pathog Dis 2011;8:1055-62.

8. Wallinga D, Burch DG. Does adding routine antibiotics to animal feed pose a serious risk to human health? Br Med J 2013;9:347-9.

9. Zhang X, Sun Z, Cao F, et al. Effects of dietary supplementation with fermented ginkgo leaves on antioxidant capacity, intestinal morphology and microbial ecology in broiler chicks. Br Poult Sci 2015;56:370-80.

10. Fard SH, Toghyani M, Tabeidian SA. Effect of oyster mushroom wastes on performance, immune responses and intestinal morphology of broiler chickens. Int J Recycl Org Waste Agric 2014;3:141-6.

11. ISA, Brown commercial management guide. Studley, UK: A hendrix genetics company; 2016 [cited 2016 Mar 25]. Available from: www.isapoultry.com

12. AOAC. Official methods for analysis, 13 th ed. Association of official analytical chemists, Washington, DC, USA: AOAC International; 2004.

13. Talapatra S, Ray S, Sen K. The analysis of mineral constituents in biological materials. Estimation of phosphorus, chlorine, calcium, manganese, sodium and potassium in foodstuffs. Indian J Vet Sci 1940;10:243-58.

14. Abdelqader A, Al-Fataftah AR, Das G. Effects of dietary Bacillus subtilis and inulin supplementation on performance, eggshell quality, intestinal morphology and microflora composition of laying hens in the late phase of production. Anim Feed Sci Technol 2013;179:103-11.

15. SPSS. Statistical software package for the social sciences. Chicago, IL, USA: 15.0, SPSS, Int.; 2006.

16. Duncan DB. Multiple range and multiple F tests. Biometrics 1955;11:1-42.

17. Pourhossein Z, Qotbi AAA, Seidavi A, et al. Effect of different levels of dietary sweet orange (Citrus sinensis) peel extract on humoral immune system responses in broiler chickens. Anim Sci J 2015;86:105-10.

18. Lee SB, Choi YH, Cho SK, et al. Effects of dietary Flammulina velutipes mycelium on broiler chick performance, pathogenic 
bacterial counts in caecal contents and amount of $\mathrm{NH}_{3}$ in excreta. J Anim Sci Technol (Korea) 2012;54:341-7.

19. Reis FS, Barros L, Martins A, Ferreira ICFR. Chemical composition and nutritional value of the most widely appreciated cultivated mushrooms: an inter-species comparative study. Food Chem Toxicol 2012;50:191-7.

20. Smiderle FR, Carbonero ER, Sassaki GL, Gorin PAJ, Iacomini M. Characterization of a heterogalactan: some nutritional values of the edible mushroom Flammulina velutipes. Food Chem 2008;108:329-33.

21. Hong-Gu L, Kiml MJ, Lee JS. Effects of dietary fermented Flammulina velutipes mycelium on performance and egg quality in laying hens. Int J Poult Sci 2014;13:637-44.

22. Na J, Jang B, Kim S, et al. Influence of feeding Flammuling veluipes media on productivity and egg quality in laying hens. Korean J Poult Sci 2005;32:143-7.

23. Miles PG, Chang ST. Mushrooms: cultivation, nutritional value, medicinal effect, and environmental impact. Second Edition. London, UK: CRC press; 2004. 451 p.

24. Daneshmand A, Sadeghi G, Karimi A. The effects of a combination of garlic, oyster mushroom and propolis extract in comparison to antibiotic on growth performance, some blood parameters and nutrients digestibility of male broilers. Braz
J Poult Sci 2012;14:141-7.

25. Jang M, Lim TG, Ahn S, et al. Immune-enhancing effects of a high molecular weight fraction of cynanchum wilfordii hemsley in macrophages and immunosuppressed mice. Nutrients 2016; 8:600.

26. Al-Khalifa H. Immunological techniques in avian studies. World's Poult Sci J 2015;72:573-84.

27. Chang KL, Hung TC, Hsieh BS, et al. Zinc at pharmacologic concentrations affects cytokine expression and induces apoptosis of human peripheral blood mononuclear cells. Nutrition 2006;22:465-74.

28. Jarosz Ł, Marek A, Grądzki Z, et al. Effect of feed supplementation with zinc glycine chelate and zinc sulfate on cytokine and immunoglobulin gene expression profiles in chicken intestinal tissue. Poult Sci 2017;96:4224-35.

29. Muthusamy G, Joardar SN, Samanta I, et al. $\beta$-Glucan from edible mushroom (Pleurotus florida) enhances mucosal immunity in poultry. Adv Anim Vet Sci 2013;1:116-9.

30. Badalyan SM, Hambardzumyan LA. Investigation of immunomodulating activity of the medicinal mushroom Flammulina velutipes (Curt.: Fr.) P. karst. In vitro. cytokine induction by fruiting body extract. Int J Med Mushrooms 2001;3:110-1. 